\title{
Detection and assessment of the emerging contaminants in Drinking Water, Slovenia
}

\author{
BRANKA BRACIC ZELEZNIK ${ }^{1}$ \\ ANJA TORKAR ${ }^{2}$ \\ MIHAEL BRENČIČ
}

${ }^{1}$ JP VOKA SNAGA d.o.o., Vodovodna cesta 90, 1000

Ljubljana,* branka.bracic.zeleznik@vokasnaga.si

${ }^{2}$ Faculty of Natural Sciebnces and Engineering, Department of Geology, Aškerčeva 12, 1000 Ljubljana

Recent researches show, how the aquatic environment, that is also the source of drinking water, contains anthropogenic substances, until few years, their presence was unknown and there are still considerable knowledge gaps. Emerging contraminants, above all pharmaceuticals and personal care products (PPCPs) are not yet listed in drinking water guidelines because many were undetectable until recently.

The development of laboratory methods and procedures and their economic feasibility bring a spectrum of new questions and challenges. An extremely varied range of substances appears in the hydrosphere of which the impact on the ecosystem, and consequently on human health in most cases is unknown. Pharmaceuticals and personal care products (PPCPs) represent a crucial yet manageable group, usually present in very low concentrations in the order of ng/l to ug/l. Their species composition is extremely diverse being mostly made up of different kinds of medicines that enter the sewer after leaving human body. Hormones, contraceptives and even narcotics are also found in water. These substances are widespread in almost all industrialized and developed countries. The highest concentrations logically occur around large urban agglomerations and medical facilities. Because PPCPs spread primarily in surface water, there are becoming the cross-border European problems.

The main objective of the boDEREC-CE project is the design of an integrated management of water works that guarantees increased quality of drinking water. The boDEREC - CE delivers a varied range of outputs, based on the knowledge about behaviour of different types of PPCPs in different types of natural environment of CE countries. We will presented the first results inside boDEREC-CE project. The test area of intergranular urban aquifer Ljubljana polje, that is the biggest drinking water source in Slovenia and river Sava, the recharge of aquifer, will be highlighted. 
This abstract is too long to be accepted for publication.

Please revise it so that it fits into the column on one page. 